\title{
Hydrotalcite as an Efficient and Reusable Catalyst for Acylation of Phenols, Amines and Thiols Under Solvent-free Conditions
}

\author{
A. R. MASSAH ${ }^{1,2}$, R. J. KALBASI ${ }^{1,2}$, M. TOGHIANI ${ }^{1}$, B. $\operatorname{HOJATI}^{1}$, AND
}

M. ADIBNEJAD ${ }^{3}$

${ }^{1}$ Department of Chemistry, Shahreza Branch, Islamic Azad University, 311-86145, Shahreza, Isfahan, Iran

${ }^{2}$ Razi Chemistry Research Center, Shahreza Branch, Islamic Azad University, Shahreza, Isfahan, 86145-311, Iran

${ }^{3}$ Department of Biochemistry, Falavarjan Branch, Islamic Azad University, 84515-155, Falavarjan, Isfahan, Iran massahar@iaush.ac.ir

Received 10 November 2011; Accepted 16 January 2012

\begin{abstract}
A wide variety of alcohols, phenols, amines and thiols were efficiently acylated with carboxylic acid anhydrides and chlorides in the presence of Hydrotalcite under solvent-free conditions at room temperature in good to high yields. Eco-friendly conditions and reusability of the catalyst are the most important advantages of this protocol.
\end{abstract}

Keywords: Hydrotalcite, Acylation, Solvent-free, Alcohols, Phenols, Amines, Thilols.

\section{Introduction}

Direct acylation of alcohols, phenols, amines and thiols is one of the most fundamental and important reactions in organic chemistry industry ${ }^{1}$. Organic esters, thioesters and amides represent an important family of intermediates widely employed in the synthesis of fine chemicals, drugs, plasticizers, perfumes, food preservatives and pharmaceuticals ${ }^{2}$. In these reactions, acid chlorides or anhydrides are often used as the acylating agents in the presence of suitable base such as triethylamine and pyridine ${ }^{3}, \mathrm{DMAP}^{4}, \mathrm{TMEDA}^{5}$ or $\mathrm{Bu}_{3} \mathrm{P}^{6}$. On the other hand, various acid catalysts such as $\mathrm{CoCl}_{2}{ }^{7}, \mathrm{ZnO}^{8}$, Nafion- ${ }^{9}, \mathrm{LiClO}_{4}{ }^{10}, \mathrm{InCl}_{3}{ }^{11}$, $\mathrm{Zn}\left(\mathrm{ClO}_{4}\right)_{2} \cdot 6 \mathrm{H}_{2} \mathrm{O}^{12}, \mathrm{ZrCl}_{4}{ }^{13}, \mathrm{P}_{2} \mathrm{O}_{5} / \mathrm{SiO}_{2}{ }^{14}, \mathrm{ZrOCl}_{2} \cdot 8 \mathrm{H}_{2} \mathrm{O}^{15}$, alumina ${ }^{16}$, and some triflates ${ }^{17-20}$, developed for acylation of phenols, thiols, and amines. However, the reported methodologies suffer from various disadvantages, for example some of the reagents are expensive and some of them difficult to handle, long reaction times, dry reaction conditions, use of hazardous materials (DMAP and 4-pyrrolidinopyridine are highly toxic, $\mathrm{Bu}_{3} \mathrm{P}$ is flammable and air sensitive) and halogenated solvents, scope for potential side reactions with acid-sensitive substrates (rearrangement, dehydration, etc.), necessitating the use of a 
large excess of acylating agents and low temperature, in addition to the use of costly catalysts. Therefore, it is desirable to develop solid base catalysts which would overcome these disadvantages and provide a commercial process having easy handling of the catalyst, easy separation of products, decreased corrosion of the reactor, and possible regeneration and re-use of the catalyst.

Hydrotalcite (HT) or Hydrotalcite-like compounds (HTlc) are layered double hydroxides belonging to the class of anionic clays. The structure of these compounds are very similar to that of brucite, $\mathrm{Mg}(\mathrm{OH})_{2}$, where some of $\mathrm{Mg}^{2+}$ represented as [M(II)] are isomorphously replaced by $\mathrm{Al}^{3+}$ represented as $[\mathrm{M}(\mathrm{III})]$ and the net positive charge is compensated by the inter-layered exchangeable anion $\left(\mathrm{A}^{\mathrm{n}-}\right)$. The general formula of these compounds can be represented as: $\left[\mathrm{M}(\mathrm{II})_{1-\mathrm{x}} \mathrm{M}(\mathrm{III})_{\mathrm{x}}(\mathrm{OH})_{2}\right] \cdot \mathrm{A}^{\mathrm{n}-\mathrm{x} / \mathrm{n}} \cdot \mathrm{mH}_{2} \mathrm{O}$. Hydrotalcite has recently received much attention as solid base catalysts. The basicity of the Hydrotalcite could be modified either by changing the divalent to trivalent cations molar ratio $[\mathrm{M}(\mathrm{II}) / \mathrm{M}(\mathrm{III})]$ or intercalation of a suitable anion in the interlayer space. These catalysts can be used for different purposes in organic chemistry, such as condensations reactions ${ }^{21}$, alkylation of phenol ${ }^{22}$, and $\mathrm{N}$ arylation of amines ${ }^{23}$.

Although numerous methods are known in the literature in order to obtain good yields of the acetylated products, still there is a great demand for mild and effective catalyst, which can be used for acylation reaction to a wide variety of substrates. In our continuing studies toward the development of solvent-free reactions ${ }^{24}$, now we introduce a simple and reliable reaction protocol for the clean, fast and high-yielding synthesis of various esters, thioesters and amides in the presence of Hydrotalcite as a base catalyst (Scheme 1). This method offers several attractive advantages over previous reported methods such as high catalyst activity, mild reaction conditions, easy recovery, reusability of the catalyst and solvent-free conditions.

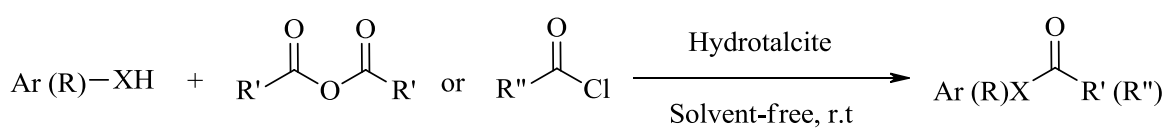

$\mathrm{X}=\mathrm{O}, \mathrm{NH}, \mathrm{S}$

\section{Scheme 1}

\section{Experimental}

\section{General procedure for acylation}

To a vigorously stirring mixture of Hydrotalcite (dry powder, $0.2 \mathrm{~g})^{25}$ and alcohol, phenol, amine or thiol $(1 \mathrm{mmol})$, 4-nitrobenzoyl chloride $(1 \mathrm{mmol})$ or anhydride (benzoic anhydride $1 \mathrm{mmol}$, acetic anhydride $4 \mathrm{mmol}$ ), were added. The reaction mixture was stirred for a certain period of time as required to complete the reaction (monitored by TLC) at room temperature. Ethyl acetate $(10 \mathrm{~mL})$ was added and the solid mass (Hydrotalcite) was then eluted with further ethyl acetate $(20 \mathrm{~mL})$, and the ethyl acetate extract was then washed with an aqueous solution of sodium bicarbonate $(10 \mathrm{~mL})$ and water $(10 \mathrm{~mL})$ and dried over anhydrous manganese sulfate. Evaporation of solvent furnished the corresponding product in high purity and does not need much purification. 


\section{Results and Discussion}

Initially, phenol and 4-methylaniline were chosen as model compounds and their acylation was examined under various reaction conditions. Under optimum conditions, phenol and 4mathylaniline (1 equiv) were acylated at room temperature almost quantitatively with benzoic anhydride ( 1 equiv) in the presence of $0.2 \mathrm{~g}$ Hydrotalcite without use of any solvents.

The generality of the method was established by efficient acylation of structurally diverse and functionalized aliphatic and aromatic alcohols, phenols and thiols. Benzoic anhydride and 4-nitrobenzoyl chloride were used as acylating agent. All of the reactions were performed in solvent-free conditions and the products obtained in good to high yield and purity after a simple work-up. The reaction of alcohols and phenols with acetic anhydride were too slow to have practical application. Compounds containing primary (Table 1, entries $1,2,8$ and 10) and secondary (Table 1, entry 9) hydroxyl groups were all readily acylated under optimum conditions without any side reactions. Also, acylation of 4-methoxybenzyl alcohol was carried out in 5 and 8 minutes with benzoic anhydride and 4-nitrobenzoyl chloride and the corresponding esters were obtained in 90 and $87 \%$ yields. Allyl alcohol was also satisfactorily acylated and no rearrangement was observed. Interestingly, phenols undergo acylation smoothly under the same reaction conditions. Phenols with electron withdrawing and donating groups undergo acylation reaction rapidly with high yield and purity. Phenols with nitro and chloro substituents as electron withdrawing group in different positions produce $70-90 \%$ yield in 5-20 min reaction time. 4-Methylphenol was acylated with 4-nitrobenzoyl chloride and give $70 \%$ of the corresponding ester in 10 min (Table 1, entry 17). Here maybe the acidity of phenols exerts significant influence on the reaction in basic conditions in the presence of Hydrotalcite. Also, the results show that acid anhydride was preferred over the acid chloride.

Table 1. Hydrotalcite catalyzed acylation of alcohols, phenols and thiols under solvent-free

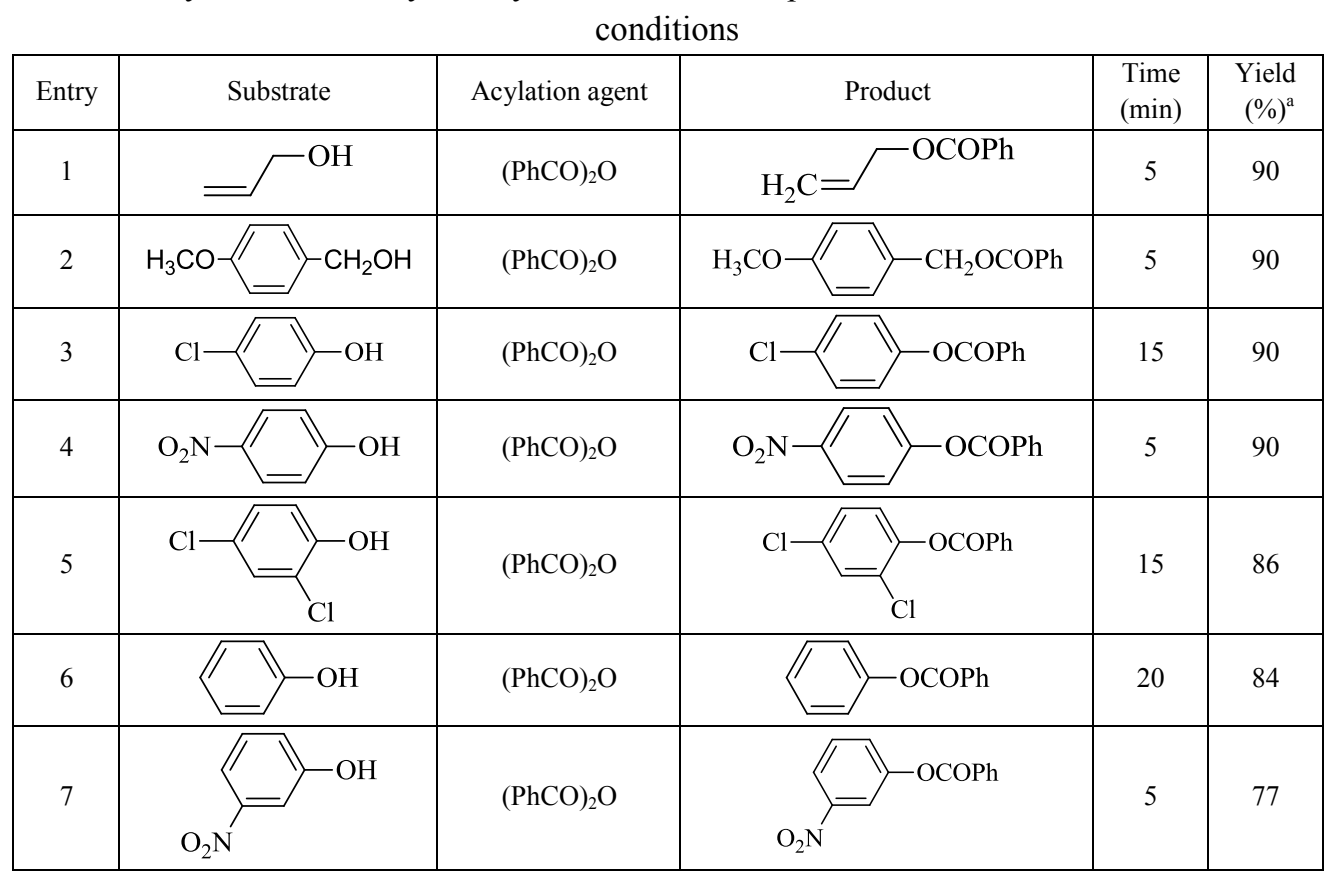




\begin{tabular}{|c|c|c|c|c|c|}
\hline 8 & $\mathrm{H}_{3} \mathrm{CO}-\backslash-\mathrm{CH}_{2} \mathrm{OH}$ & $4-\mathrm{NO}_{2} \mathrm{PhCOCl}$ & $\mathrm{H}_{3} \mathrm{CO}-\mathrm{CH}_{2} \mathrm{OCOPhNO}$ & 8 & 87 \\
\hline 9 & & 4- $\mathrm{NO}_{2} \mathrm{PhCOCl}$ & $\mathrm{H}_{3} \mathrm{C}-\mathrm{OCOPhNO}_{2}$ & 5 & 79 \\
\hline 10 & $\mathrm{Ph}^{-}$ & $4-\mathrm{NO}_{2} \mathrm{PhCOCl}$ & $\mathrm{OPhNO}_{2}$ & 5 & 81 \\
\hline 11 & & $4-\mathrm{NO}_{2} \mathrm{PhCOCl}$ & $\mathrm{COPhNO}_{2}$ & 5 & 75 \\
\hline 12 & $\mathrm{O}_{2} \mathrm{~N}$ & $4-\mathrm{NO}_{2} \mathrm{PhCOCl}$ & & 20 & 70 \\
\hline 13 & & $4-\mathrm{NO}_{2} \mathrm{PhCOCl}$ & $\mathrm{NO}_{2}$ & 10 & 82 \\
\hline 14 & & 4- $\mathrm{NO}_{2} \mathrm{PhCOCl}$ & & 15 & 71 \\
\hline 15 & $\mathrm{OH}$ & $4-\mathrm{NO}_{2} \mathrm{PhCOCl}$ & $\mathrm{OCOPhNO}_{2}$ & 15 & 72 \\
\hline 16 & $-\mathrm{OH}$ & $4-\mathrm{NO}_{2} \mathrm{PhCOCl}$ & $-\mathrm{OCOPhNO}_{2}$ & 15 & 78 \\
\hline 17 & - $\mathrm{OH}$ & $4-\mathrm{NO}_{2} \mathrm{PhCOCl}$ & $-\mathrm{OCOPhNO}_{2}$ & 10 & 70 \\
\hline 18 & & $4-\mathrm{NO}_{2} \mathrm{PhCOCl}$ & & 2 & 85 \\
\hline 19 & & $(\mathrm{PhCO})_{2} \mathrm{O}$ & & 6 & 94 \\
\hline
\end{tabular}

${ }^{\mathrm{a}}$ Isolated Yield.

Although recently there has been an upsurge in the use of acid catalyst for acylation reactions, they are unsuitable for their use in dealing with acid-sensitive substrates such as amines and mostly they were used for acylation of alcohols and phenols. To extend the scope and the generality of Hydrotalcite-catalyzed acylation reactions, a wide range of aliphatic and aromatic amines containing both electron withdrawing and donating groups in the aromatic ring underwent the acylation in quantitative yields in most cases. The experimental results are summarized in Table 2. In spite of the fact that the presences of the chloro and nitro group(s) in the aromatic amines make the amino group of these substrates poor nucleophilic, good to excellent yields of the corresponding amides were obtained at room temperature under solvent-free conditions in the presence of Hydrotalcite. It is significant to note that acid anhydrides were preferred to the acid chlorides. The reactions of amines with $\mathrm{Ac}_{2} \mathrm{O}$ were so fast in comparison to those of the aliphatic alcohols that the selective protection of an amine in the presence of aliphatic alcohols appeared to be a distinct possibility. 
Table 2. Hydrotalcite catalyzed acylation of amines under solvent-free conditions.

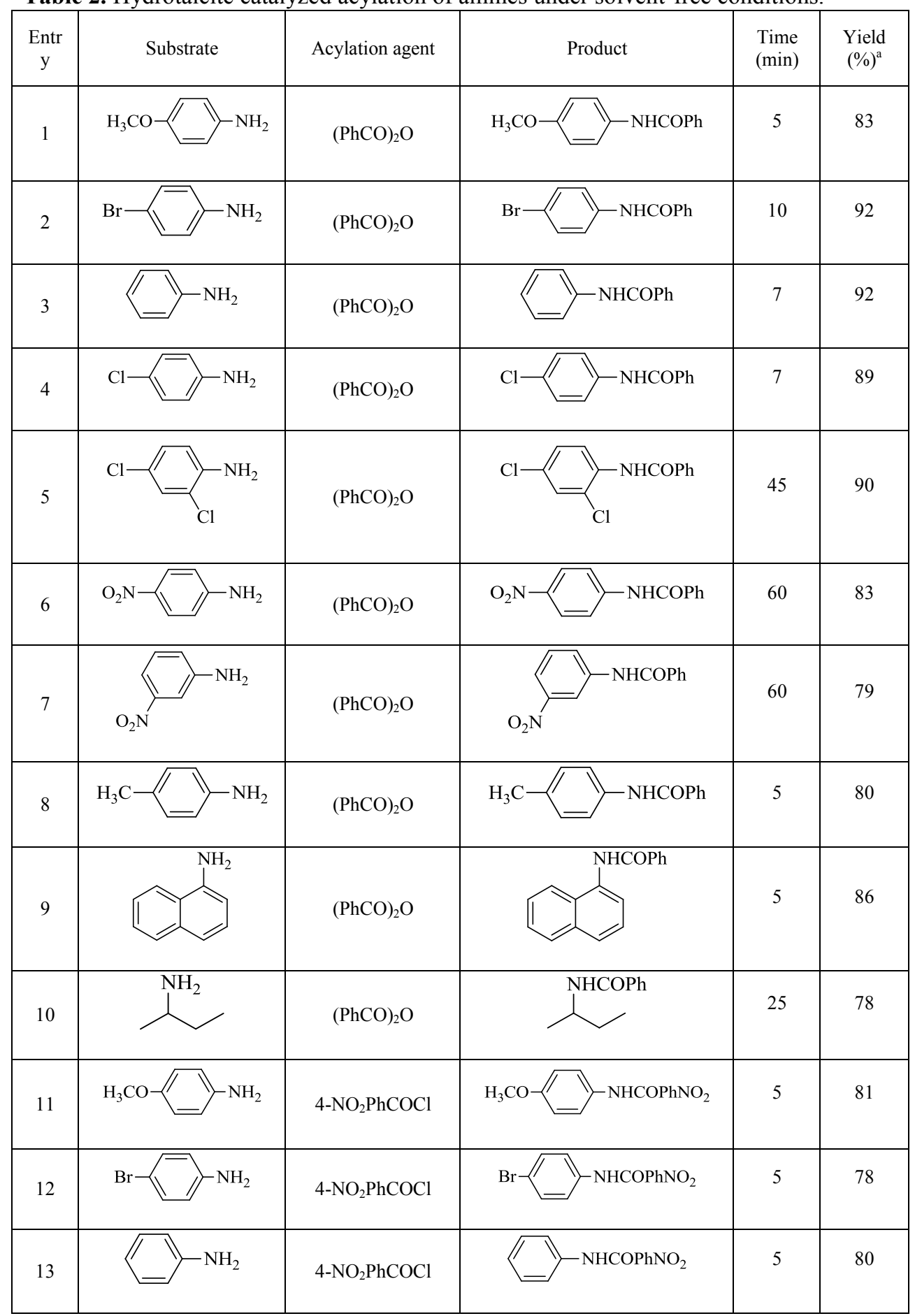




\begin{tabular}{|c|c|c|c|c|c|}
\hline 14 & $\mathrm{Cl}-\mathrm{NH}_{\mathrm{Cl}}$ & $4-\mathrm{NO}_{2} \mathrm{PhCOCl}$ & Cl $\mathrm{NHCOPhNO}_{2}$ & 30 & 85 \\
\hline 15 & $\mathrm{O}_{2} \mathrm{~N} \longrightarrow-\mathrm{NH}_{2}$ & $4-\mathrm{NO}_{2} \mathrm{PhCOCl}$ & $\mathrm{O}_{2} \mathrm{~N}-\longrightarrow-\mathrm{NHCOPhNO}_{2}$ & 50 & 68 \\
\hline 16 & $\mathrm{H}_{3} \mathrm{C}$ & $4-\mathrm{NO}_{2} \mathrm{PhCOCl}$ & $\mathrm{H}_{3} \mathrm{C}-\mathrm{NHCOPhNO}_{2}$ & 5 & 88 \\
\hline 17 & & $4-\mathrm{NO}_{2} \mathrm{PhCOCl}$ & & 10 & 82 \\
\hline 18 & $\mathrm{NH}_{2}$ & $4-\mathrm{NO}_{2} \mathrm{PhCOCl}$ & $\mathrm{NHCOPhNO}_{2}$ & 10 & 80 \\
\hline 19 & $\mathrm{H}_{3} \mathrm{CO}$ & $\left(\mathrm{CH}_{3} \mathrm{CO}\right)_{2} \mathrm{O}$ & $-\mathrm{NHCOCH}_{3}$ & 10 & 72 \\
\hline 20 & $\mathrm{H}_{3} \mathrm{C}$ & $\left(\mathrm{CH}_{3} \mathrm{CO}\right)_{2} \mathrm{O}$ & $-\mathrm{NHCOCH}_{3}$ & 10 & 98 \\
\hline 21 & $-\mathrm{NH}_{2}$ & $\left(\mathrm{CH}_{3} \mathrm{CO}\right)_{2} \mathrm{O}$ & $-\mathrm{NHCOCH}_{3}$ & 10 & 72 \\
\hline 22 & $-\mathrm{NH}_{2}$ & $\left(\mathrm{CH}_{3} \mathrm{CO}\right)_{2} \mathrm{O}$ & $-\mathrm{NHCOCH}_{3}$ & 5 & 74 \\
\hline 23 & $\mathrm{O}_{2} \mathrm{~N}^{\prime}$ & $\left(\mathrm{CH}_{3} \mathrm{CO}\right)_{2} \mathrm{O}$ & & 5 & 72 \\
\hline 24 & $-\mathrm{NH}_{2}$ & $\left(\mathrm{CH}_{3} \mathrm{CO}\right)_{2} \mathrm{O}$ & $-\mathrm{NHCOCH}_{3}$ & 5 & 83 \\
\hline 25 & $\mathrm{Cl}-$ & $\left(\mathrm{CH}_{3} \mathrm{CO}\right)_{2} \mathrm{O}$ & $-\mathrm{NHCOCH}_{3}$ & 5 & 87 \\
\hline 26 & $\mathrm{NH}_{2}$ & $\left(\mathrm{CH}_{3} \mathrm{CO}\right)_{2} \mathrm{O}$ & $\mathrm{NHCOCH}_{3}$ & 5 & 76 \\
\hline
\end{tabular}

${ }^{\mathrm{a}}$ Isolated Yield.

Additionally, the catalytic activity of reused Hydrotalcite, which was readily recovered by filtration of the reaction mixture and consequent washing with ethyl acetate, was investigated. Acylation of 4-methylaniline with benzoic anhydride and 4-nitrobenzoyl 
chloride in the presence of twice or three times recycled Hydrotalcite led the corresponding amide, in comparable yields to the fresh catalyst.

\section{Conclusion}

We have developed a simple, efficient and catalytic method for the preparation of various esters, amides and thioesters from the corresponding alcohols, phenols, amines and thiols by employing Hydrotalcite as catalyst under solvent-free conditions. The notable special features of this methodology are the simple reaction procedure, good yields of products, low cost, ready availability and recyclability of the catalyst under neat conditions. Thus, this methodology represents a better, eco-friendly alternative to many existing procedures and is also suitable for industrial applications.

\section{Acknowledgment}

We appreciate financial support of Shahreza Branch, Islamic Azad University and Falavarjan Branch, Islamic Azad University Research Councils.

\section{References}

1. Greene T W and Wuts P G M, Protective Groups in Organic synthesis, 3rd ed, John Wiley \& Sons, Inc, New York, 1999, 150- 160.

2. Sano T, Ohashi K and Oriyama T, Synthesis, 1999, 7, 1141.

3. (a) Zhdanov R I and Zhenodarova S M, Synthesis, 1975, 222 (b) Horton D, Org. Synth., 1973, 5, 1 .

4. Steglich W and Hofle G, Angew. Chem., Int. Ed. Engl., 1969, 8,981.

5. Santosh T K, Hanbin L and Sung S K, Bull. Korean Chem. Soc., 2009, 30, 1071.

6. Vedejs E and Diver S T, J. Am. Chem. Soc., 1993, 115, 3358.

7. Iqbal J, Srivastava R R, J. Org. Chem., 1992, 57, 2001.

8. Hosseini Sarvari M and Sharghi H, Tetrahedron, 2005, 61, 10903-10907.

9. Kumareswaran R, Pachamuthu K and Vankar Y D, Synlett., 2000, 1652.

10. Nakae Y, Kusaki I, Sato T, Synlett., 2001, 1584.

11. Chakraborti A K and Gulhane R, Tetrahedron Lett., 2003, 44, 3521.

12. Bartoli G, Bosco M, Dalpozzo R, Marcantoni E, Massaccesi M and Sambri L, Eur. J. Org. Chem., 2003, 4611.

13. Chakraborti A K and Gulhan R, Synlett, 2004, 627.

14. Eshghi H and Shafieyoon P J, Chem. Res., 2004, S, 802.

15. Ghosh R, Maiti S and Chakraborty A, Tetrahedron Lett., 2005, 46, 147.

16. Yadav V K and Babu K G, J. Org. Chem., 2004, 69, 577.

17. Procopiou, P A, Baugh, S P D, Flack, S S and Inglis G G A, J. Org. Chem., 1998, 63, 2342.

18. (a) Saravanan P and Singh V K, Tetrahedron Lett., 1999, 40, 2611; (b) Chandra K L, Saravanan P, Singh R K and Singh V K, Tetrahedron, 2002, 58, 1369.

19. Dalpozzo R, Nino A D, Maiuolo L, Procopio A, Nardi M, Bartoli G and Romeo R, Tetrahedron Lett., 2003, 44, 5621. 
20. Orita A, Tanahashi C, Kakuda A and Otera J, Angew. Chem., Int. Ed., 2000, 39, 2877.

21. (a) Reichle W T , J. Catal., 1980, 63, 295 (b) Climent M J, Corma A, Iborra S and Velty A, J. Mol. Catal., 2002, 327, 182-183 (c) Sharma S K, Parikh P A and Jasra R V, J. Mol. Catal. A: Chem., 2008, 286, 55-62; (d) Tichit D, Lutic D, Coq B, Durand R and Teissier R, J. Catal., 2003, 219, 167-175.

22. Padmasri A H, Venugopal A, Durga Kumari V, Rama Rao K S and Kanta Rao P, J. Mol. Catal. A: Chem., 2002, 188, 255-265.

23. Jadhav V H, Dumbre D K, Phapale V B, Borate H B and Wakharkar R D, Catal. Commun., 2007, 8, 65-68.

24. (a) Massah A R, Asadi B, Hoseinpour M, Molseghi A, Kalbasi R J and Javaherian N H, Tetrahedron, 2009, 65, 7696 (b) Massah A R, Adibi H, Khodarahmi R, Abiri R, Majnooni M B, Shahidi S, Asadi B, Mehrabi M and Zolfigol M A, Bioorg. Med. Chem., 2008, 16, 5465 (c) Massah A R, Azadi B, Aliyan H, Momeni A R, Javaherian N H and Kazemi F, Monatsh. Chem., 2008, 139, 233 (d) Kalbasi R J, Massah A R and Barkhordari Z, Bull. Korean. Chem. Soc., 2010, 31, 2361 (e) Massah A R, Dabagh M, Afshar M, Momeni A R, Aliyan H and Javaherian N H, Turk J. Chem., 2007, 31, 611 (f) Kalbasi R J, Kolahdoozan M, Massah A R and Shahabian K, Bull. Korean. Chem. Soc., 2010, 31, 2618 (g) Kazemi F and Massah A R, Tetrahedron, 2007, 63, 5083.

25. Cavani F, Trifiro F and Vaccari A, Catal. Today, 1991, 11, 173-301. 


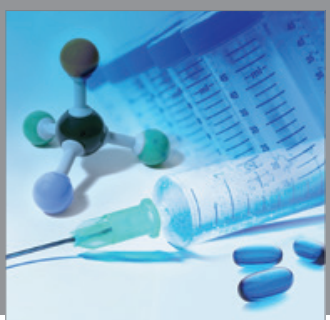

International Journal of

Medicinal Chemistry

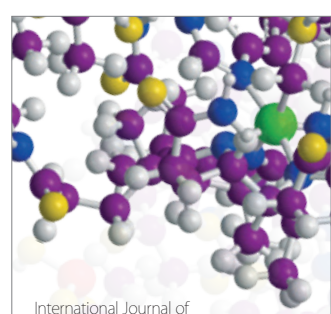

Carbohydrate Chemistry

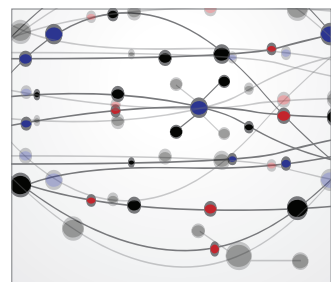

The Scientific World Journal
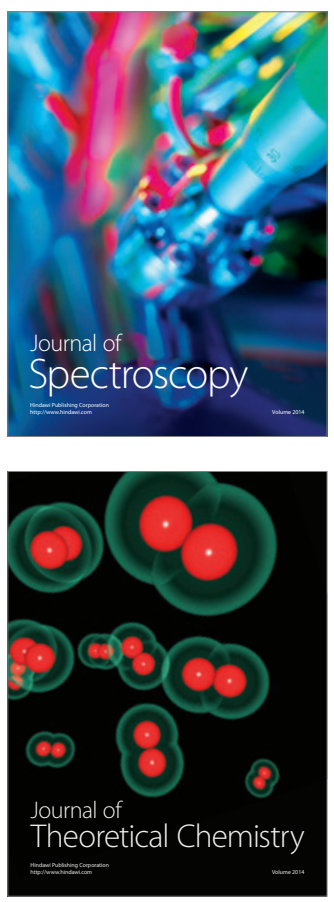
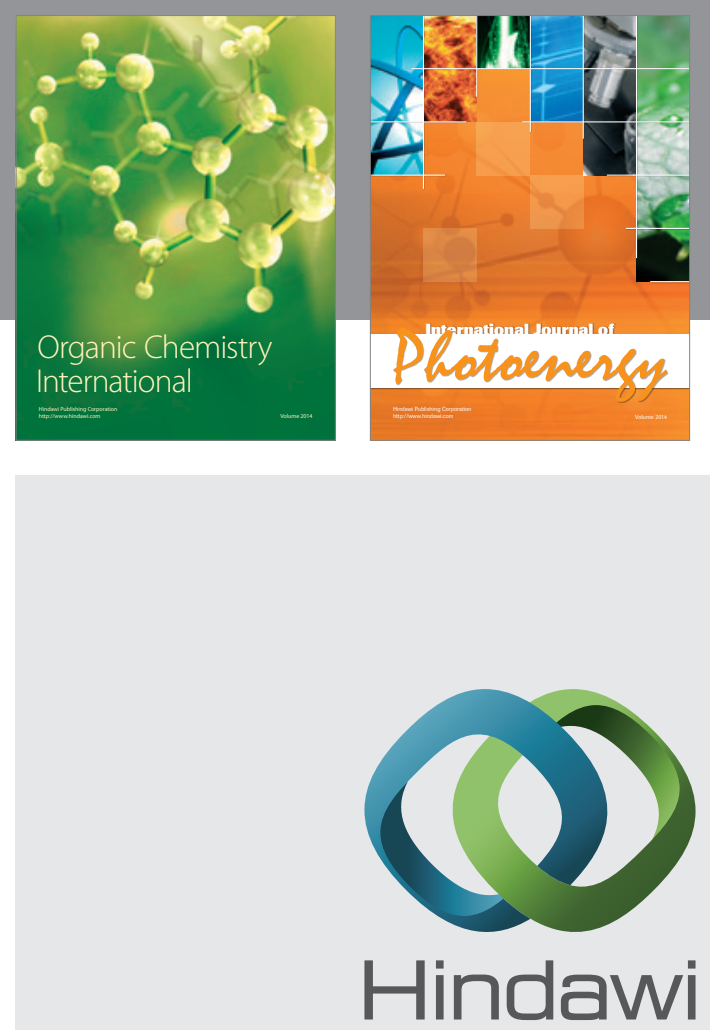

Submit your manuscripts at

http://www.hindawi.com
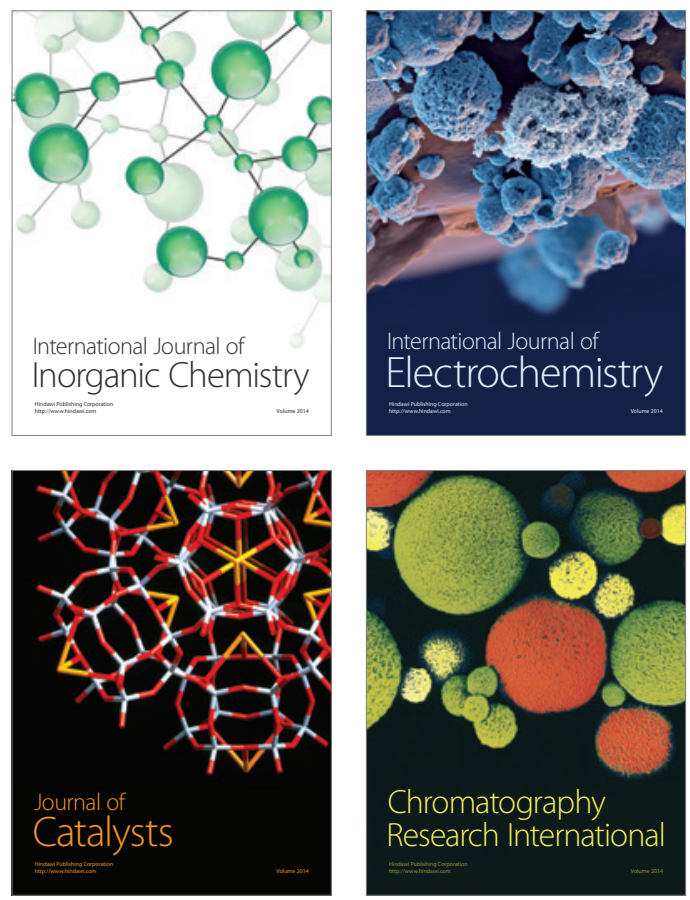
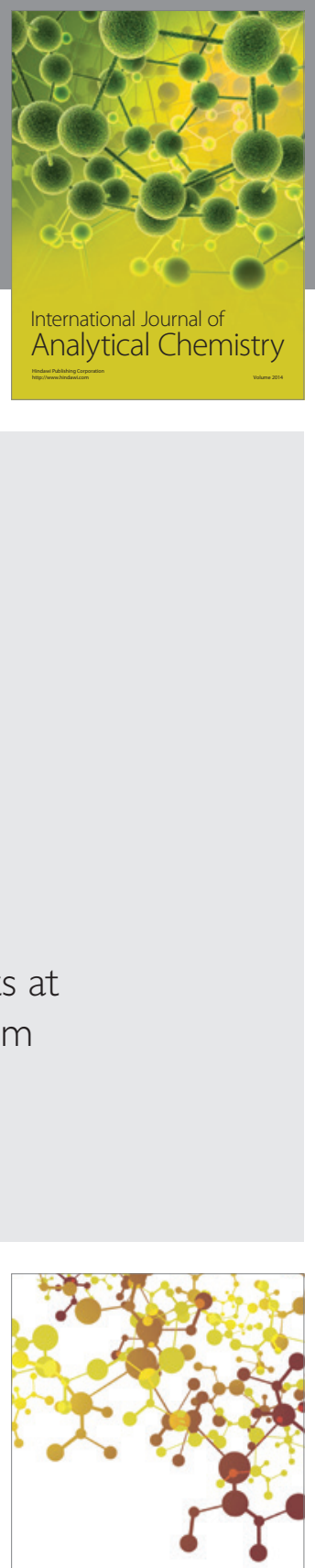

Journal of

Applied Chemistry
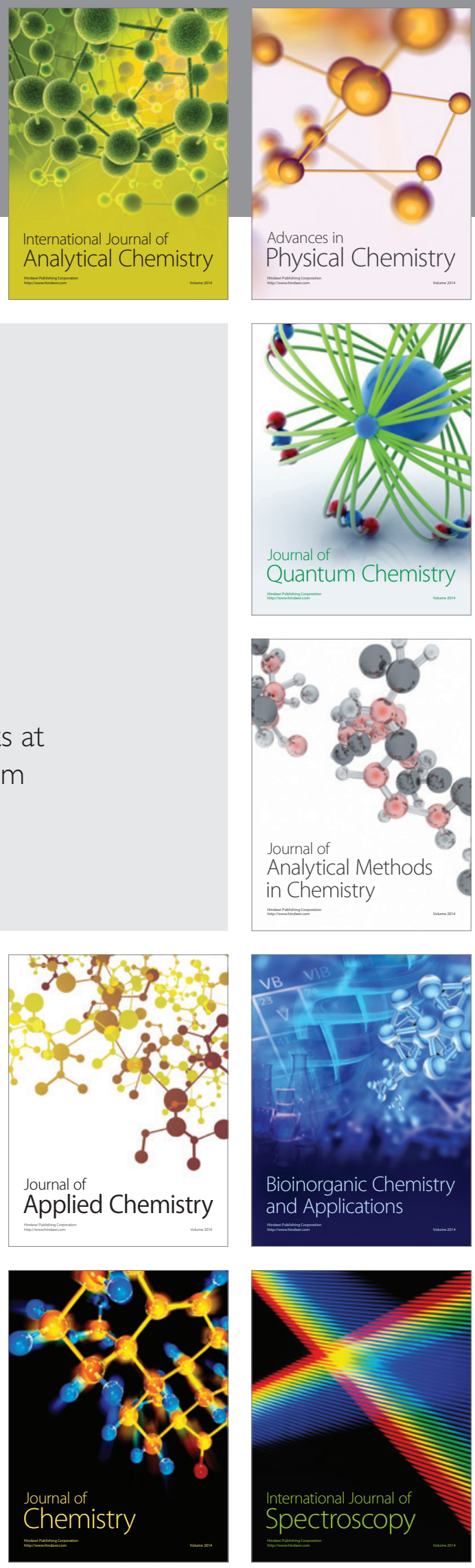